\title{
An Overview on Niosomes: A Drug Nanocarrier
}

\author{
Mahmoud Kamal ${ }^{1}$, Mohamed Maher ${ }^{1}$, Amr Ibrahim $^{1}$ and Dina Louis ${ }^{1,2 *}$ \\ ${ }^{1}$ Faculty of Pharmacy and Drug Technology, Heliopolis University, Egypt \\ ${ }^{2}$ Pharmaceutics and Industrial Pharmacy Department, Faculty of Pharmacy, Cairo University, Cairo, Egypt
}

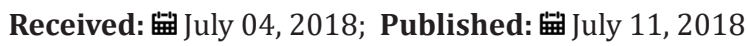

*Corresponding author: Dina Louis, Department of Pharmaceutics and Industrial Pharmacy, Faculty of Pharmacy, Cairo University, Kasr Eleini Street, Cairo, Egypt

\begin{abstract}
Niosome are non-ionic surfactant vesicles acquired on hydration of synthetic nonionic surfactants, with or without consolidation of cholesterol or their lipids. They are vesicular systems like liposome's that can be utilized as transporters of amphiphilic and lipophilic medications. Niosomes are promising vehicle for drug delivery and being non-ionic; and Niosomes are biodegradable, biocompatible non immunogenic and show adaptability and flexibility in their structural characterization. Niosomes have been generally assessed for controlled discharge and targeted delivery for the treatment of tumor, viral infections and other microbial illnesses. Niosomes can entangle both hydrophilic and lipophilic medications and can prolong the circulation of the entrapped medication in body. Encapsulation of medication in vesicular system can be anticipated to delay the presence of medication in the systemic circulation and enhance penetration into target tissue, maybe decrease toxicity if specific take-up can be accomplished. This review focuses on components of niosomes, types, the advantages, preparation methods, factors affecting, characterizations, and applications of noisome.
\end{abstract}

Keywords: Niosomes; Non-Ionic Surfactants; Cholesterol; Charged Molecules; Types; Preparation Methods; Characterization; Advantages; Applications

\section{Introduction}

As of late, vesicles have turned out to become the vehicle of choice in drug delivery. Lipid vesicles have important role in improving bioavailability for existing drugs that are mainly available in conventional dosage forms. It was found to be of value in immunology, membrane biology, diagnostic techniques, and most recently, genetic engineering. Vesicles can assume a critical role in modeling biological membranes, and in the transport and targeting of active agents. Conventional chemotherapy for the treatment of intracellular infections is not effective, because of constrained penetration of medications into cells. This was be overcome by utilization of vesicular drug delivery systems. Encapsulation of a medication in vesicular structures is expected to predict the presence of the medication in systemic circulation, and the possible decrease in the toxicity if specific take-up is accomplished. The phagocytic uptake of drug loaded vesicular delivery system gives a proficient technique for delivery of drug directly to the site of infection, prompting decrease of medication toxicity with no unfavorable effects. Vesicular drug delivery diminishes the cost of treatment by enhanced bioavailability of solution, particularly in the event of inadequately dissolvable medications. They can consolidate both hydrophilic and lipophilic medications. Vesicular drug delivery systems delay drug elimination of rapidly metabolized drugs, and function as sustained release systems. This system solves issues of medication insolubility, instability, and rapid degradation. Thus, various vesicular delivery systems for example, liposome's, niosomes, pharmacosomes and so on, were developed [1]. Niosomes are novel drug delivery systems, in which the medication is encapsulated in a vesicle. The vesicle is made of a bilayer of non-ionic surface active agents and subsequently the name niosomes. The niosomes are very small, where their size lies in the nanometric scale [1]. Although structurally similar to liposome's, they offer several advantages over them. Niosomes have shown to greatly increase transdermal drug delivery and also they can be used in targeted drug delivery [2]. Niosomes are non-ionic surfactant vesicles obtained on hydration of manufactured nonionic surfactants, with or without joining of cholesterol or other lipids. They are vesicular systems like liposome's that can be utilized as carriers of amphiphilic and lipophilic medications. Niosomes are promising vehicles for drug delivery and, being non-ionic, it is less 
dangerous and enhances the therapeutic index of drug by confining its activity to target cells [2].

\section{Components of Niosomes}

\section{Niosomes Mainly Contain Following Components}

\section{Non-Ionic Surfactants}

The non-ionic surfactants situate themselves in bilayer lattices where the polar or hydrophilic heads adjust themselves, confronting a watery mass (media) while the hydrophobic head or hydrocarbon portions align in such a way that the interaction with the aqueous media would be limited. To achieve thermodynamic stability, each bilayer creases over itself as consistent film i.e. shapes vesicles so that hydrocarbon/water interface remains no more exposed [3]. The following types of non-ionic surfactants are utilized for the formation of niosomes:

Alkyl Ethers: L'Oreal described some surfactants for the preparation of niosomes containing drugsasC16 mono alkyl glycerol ether with average of three glycerol units, with molecular weight of 473. Diglycerol ether (MW 972) is another surfactant with an average of the seven glycerol units. An ester linked surfactant (MW 393) is another example [3]. Other than alkyl glycerol, alkyl glycosides and alkyl ethers bearing poly hydroxyl head groups are also utilized in formulation of niosomes [3].

Alkyl Esters: Sorbitan esters are surfactants favored for utilization in the preparation of niosomes. Vesicles prepared by the polyoxyethylenesorbitanmonolaurate are generally soluble than other surfactant vesicles. For instance polyoxyethylene (polysorbate 60 ) has been used for encapsulation of diclofenac sodium. A blend of polyoxyethylene-10-stearyl ether: glyceryl laurate: cholesterol (27:15:57) has been utilized as a part of transdermal delivery of cyclosporine-A.

Alkyl Amides: Alkyl amide (e.g. galactosides and glucosides) have been used to deliver niosomal vesicles [3].

Fatty Acid and Amino Acid Compounds: Long chain fatty acids and amino acid moieties have also been used in some niosomes preparation [3].

\section{Cholesterol}

Steroids are critical parts of the cell film and their presence influence the bilayer fluidity and penetrability. Cholesterol is a steroid derivative, which is mainly utilized for the formulation of niosomes. Despite the fact that it may not demonstrate any part in the formation of bilayer, its significance in formation of niosomes and control of layer attributes cannot be disposed of [3]. Inclusion of cholesterol influences properties of niosomes like membrane permeability, inflexibility, encapsulation efficiency, simplicity of rehydration of freeze dried niosomes and their harmfulness. It keeps the vesicle accumulation by the consideration of atoms that balance the system against the formation of aggregates by repulsive steric or electrostatic forces that prompts the change from the gel to the liquid phase in niosome systems. Thus, the niosome turns out to be less leaky in nature [3].

\section{Charged Molecule}

Some charged molecules are added to niosomes to increase stability of niosomes by electrostatic repulsion to avoid coalescence. The negatively charged molecules utilized are diacetyl phosphate (DCP) and phosphotidic acid. Similarly, stearyl amine (STR) and stearylpyridinium chloride are well known positively charged molecules utilized in niosomal preparations. A concentration of 2.5-5 mole percentage of charged molecules is tolerable because higher concentration can hinder the niosome formation [3].

\section{Structure of Niosomes}

Niosomes are microscopic lamellar structures, which are shaped on the admixture of non-ionic surfactant and cholesterol with resulting hydration in aqueous media. Structurally, niosomes are like liposomes, in that they are comprised of a bilayer. However, the bilayer in the case of niosomes is made up of non-ionic surface active agents rather than phospholipids as with liposome's. Most surface active agents when submerged in water yield amicellar structure. However some surfactants can yield bilayer vesicles which are niosomes. Niosomes might be unilamellar or multi lamellar relying upon the technique used to set them up. The hydrophilic ends of the surfactant bilayer are exposed on the outside and inside of the vesicle, while the hydrophobic chains face each other within the bilayer. Thus, the vesicle holds hydrophilic medications inside the space encased in the vesicle, while hydrophobic medications are installed inside the bilayer itself [4] (Figure 1).

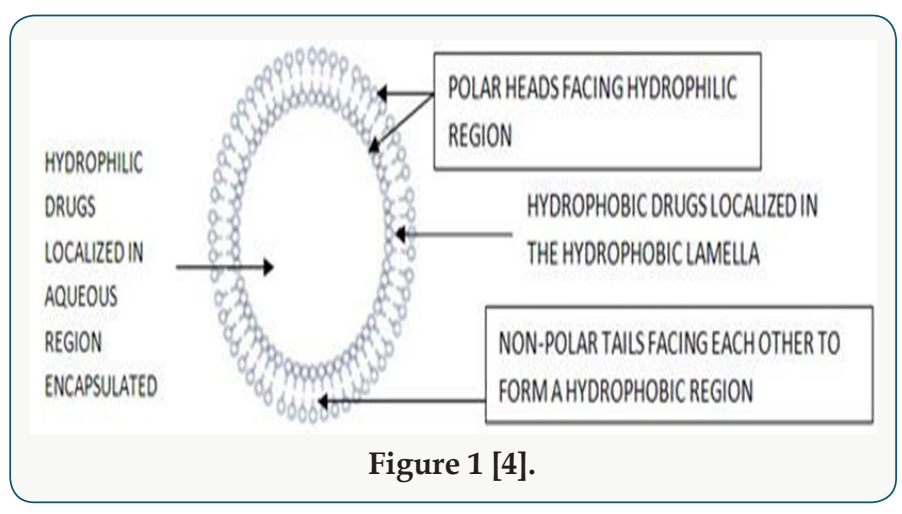

\section{Types of Niosomes}

Small Unilamellar Vesicles: These are usually created by sonication and French Press systems. Ultrasonic electro capillary emulsification or solvent dilution technique can be utilized to prepare SUVs. The inexact size of these vesicles is $0.025-0.05 \mu \mathrm{m}$ [5].

Multi lamellar Vesicles: It comprises of various bilayers encompassing the aqueous lipid compartment independently and display expanded trapped volume and equilibrium solute distribution, and requires hand-shaking method. They indicate varieties in lipid composition. The inexact size of these vesicles is 0.5-10 $\mu \mathrm{m}$ diameter [5]. 
Large Unilamellar Vesicles: The infusions of lipids solubilized in an organic solvent into an aqueous buffer, can bring spontaneous development of LUV. Preparation of LUV can best be brought about reverse phase evaporation, or by detergent solubilization method. These rough vesicles reach a size of more than $0.10 \mu \mathrm{m}[5]$ (Figure 2).

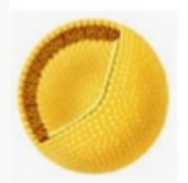

Small
Unilamellar
Vesicle
(SUV)

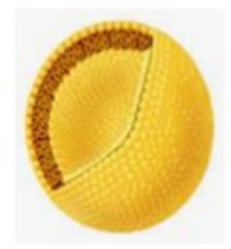

Large Unilamellar Vesicle (LUV)

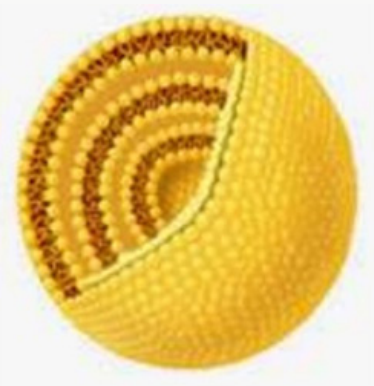

Multilamellar vesicles(MLV)

Figure 2 [5].

\section{Methods of Preparation}

\section{Ether Injection Method}

This technique prepares niosomes by gradually introducing a solution of surfactant dissolved in diethyl ether into warm water kept at $60^{\circ} \mathrm{C}$. The surfactant mixture in ether is injected through 14-gauge needle into an aqueous solution of material. Vaporization of ether leads to formation of single layered vesicles. Utilizing such conditions, results in vesicles having a width of 50 to $1000 \mathrm{~nm}$ [6].

\section{Hand Shaking Method (Thin Film Hydration Technique)}

The blend of vesicle-forming ingredients like surfactant and cholesterol are dissolved in a volatile organic solvent (diethyl ether, chloroform or methanol) in a round bottom flask. The organic solvent is expelled at room temperature $\left(20^{\circ} \mathrm{C}\right)$ using rotary evaporator leaving a thin layer of solid mixture deposited on the wall of the flask. The dried surfactant film can be rehydrated with aqueous phase at $0-60^{\circ} \mathrm{C}$ with gentle agitation. This procedure forms typical multi lamellar niosomes. Thermo sensitive niosomes were set up by Raja Naresh et al by evaporating the organic solvent at $60^{\circ} \mathrm{C}$ and leaving a thin film of lipid on the wall of rotary flash evaporator. The aqueous stage containing drug was included gradually with intermittent shaking of flask at room temperature took after by sonication $[7,8]$ (Figure 3).

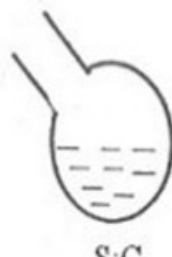

$\mathrm{S:C}$
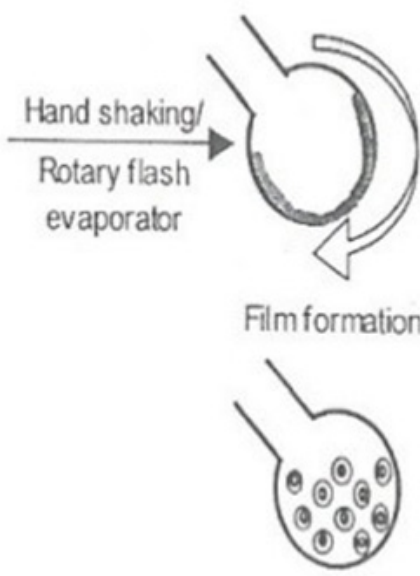

niosomal dispersion

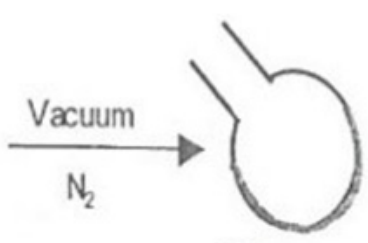

Dried film

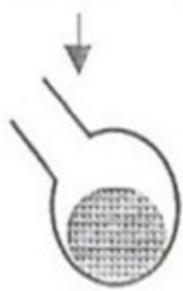

Film stacks dispersed in aqueous phase

Figure 3 [8].

\section{Sonication}

It is a strategy for creation of the vesicles as described by Cable. In this technique an aliquot of drug solution in buffer is added to the surfactant/cholesterol mixture in a 10 -ml glass vial. The mixture is probe sonicated at $60^{\circ} \mathrm{C}$ for 3 minutes using a sonicator with a titanium probe to yield niosomes [9] (Figure 4). 


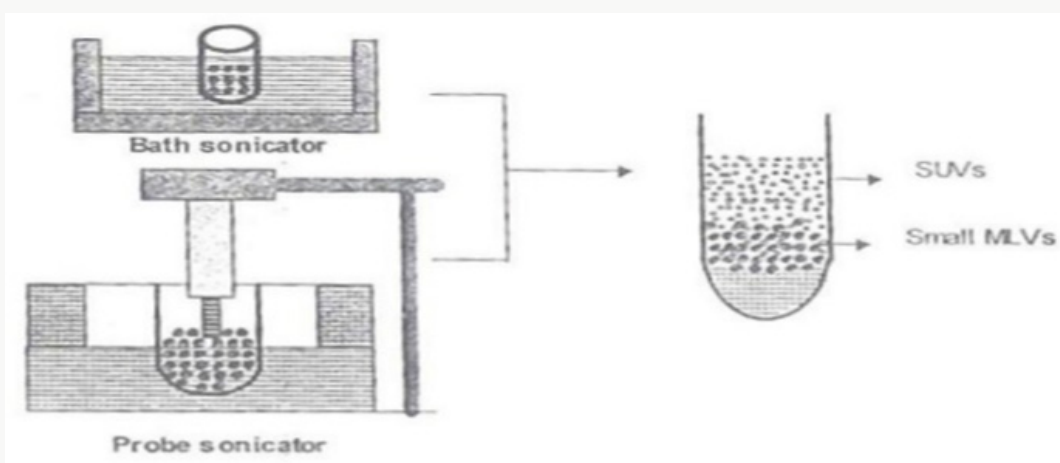

Figure 4 [8].

\section{Micro Fluidization}

Micro fluidization is a recent procedure used to prepare unilamellar vesicles of defined size distribution. This technique depends on submerged jet principle in which two fluidized streams interact at ultra-high velocities, in precisely defined micro channels within the interaction chamber. The impingement of thin fluid sheet along a typical front is managed such that the energy supplied to the system remains within the area of niosome formation. The outcome is smaller size and better reproducibility of niosomes formed [9].

\section{Multiple Membrane Extrusion Method}

A blend of surfactant, cholesterol and diacetyl phosphate is prepared and after that solvent is evaporated utilizing rotary vacuum evaporator to leave a thin film. The film is then hydrated with aqueous drug solution and the suspension subsequently acquired is extruded through the polycarbonate layer (mean pore size $0.1 \mathrm{~mm}$ ) and then placed in series up to eight passages to get uniform size niosomes good technique for controlling niosome size [9,10] (Figure 5).

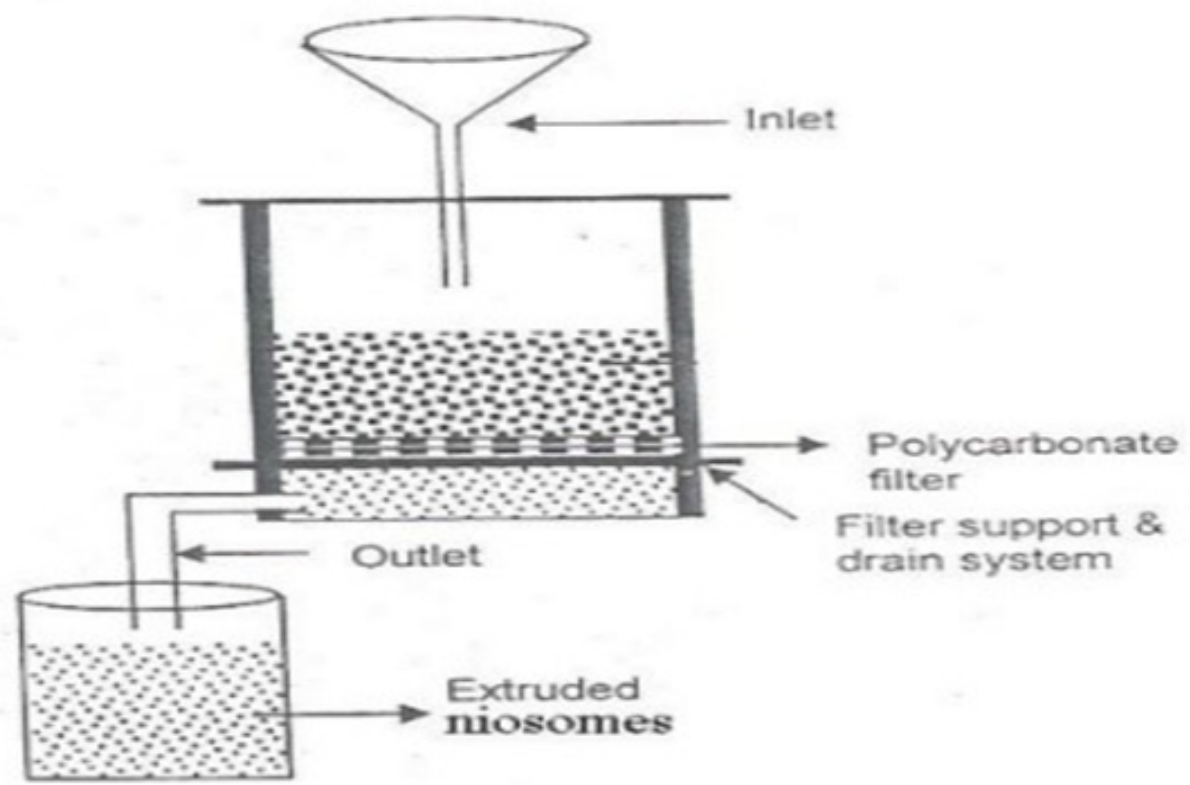

Figure 5 [10].

\section{Reverse Phase Evaporation Technique (REV)}

Both cholesterol and surfactant (1:1) are dissolved in a mixture of ether and chloroform. An aqueous phase containing drug is added to this mixture and the subsequent two phases are sonicated at $4-5^{\circ} \mathrm{C}$. The clear gel formed is further sonicated after the addition of a small amount of phosphate buffered saline (PBS). The organic phase is removed at $40^{\circ} \mathrm{C}$ under low pressure. The resulting viscous niosome suspension is diluted with PBS and warmed on a water bath at $60^{\circ} \mathrm{C}$ for $10 \mathrm{~min}$ to get niosomes [11].
Trans-Membrane pH Gradient (Inside Acidic) Drug Uptake Process (Remote Loading)

In this process, a solution of surfactant and cholesterol is made in chloroform. The solvent is then evaporated under decreased pressure to get a thin film on the wall of the round bottom flask, similar to the hand shaking method. This film is then hydrated utilizing citric acid solution ( $300 \mathrm{mM}, \mathrm{pH} 4.0)$ by vortex mixing. The resulting multi lamellar vesicles are then treated to three freeze thaw cycles and sonicated. To the niosomal suspension, aqueous 
solution containing $10 \mathrm{mg} / \mathrm{ml}$ of drug is added and vortexed. The $\mathrm{pH}$ of the sample is then increased to 7.0-7.2 using $1 \mathrm{M}$ disodium phosphate (this causes the medication which is outside the vesicle to become non-ionic and can then cross the niosomal membrane, and once inside it is again ionized thus not allowing it to exit the vesicle). The blend is later warmed at $60^{\circ} \mathrm{C}$ for 10 minutes to give niosomes [12].

\section{The Bubble Method}

It is a procedure which has just as of late been created and which permits the preparation of niosomes without the utilization of organic solvents. The bubbling unit comprises of a round bottom flask with three necks, and this is positioned in a water bath to control the temperature. Water-cooled reflux and thermometer is positioned in the first and second neck, while the third neck is used to supply nitrogen. Cholesterol and surfactant are dispersed together in a buffer $(\mathrm{pH} 7.4)$ at $70^{\circ} \mathrm{C}$. This dispersion is mixed for a period of 15 seconds with high shear homogenizer and immediately afterwards, it is bubbled at $70^{\circ} \mathrm{C}$ using the nitrogen gas to yield niosomes [13] (Figure 6).

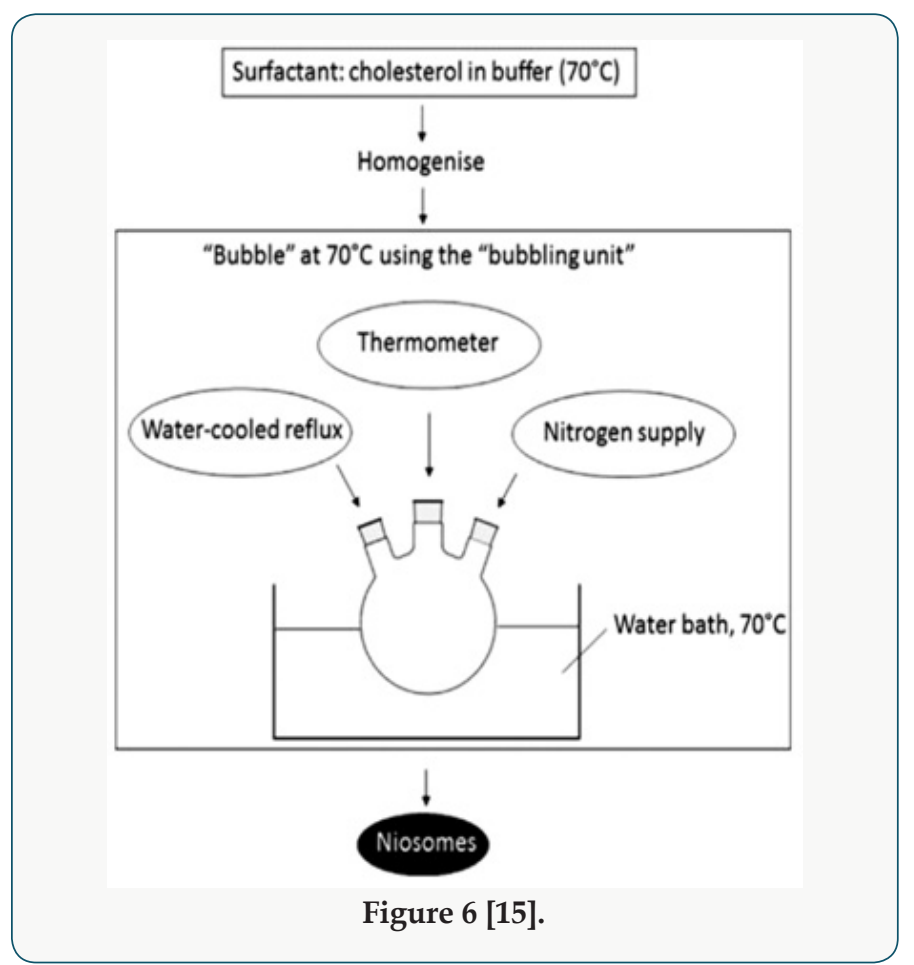

\section{Lipid Layer Hydration Method}

Span 60 and cholesterol (1:1) are dissolved in chloroform and the solvent was evaporated utilizing rotary flash evaporator. Phosphate buffer saline PH 7.4 containing drug is added to the dried thin film with gentle agitation. The blend is irregularly mixed on a vortex mixer. Sonic dispersion of the blend is completed at 250C utilizing probe sonicator set at 200 watts for 1 minute [14].

\section{Drugs Incorporated into Niosomes by Various Methods}

Table 1 [15].
Table 1 [15].

\begin{tabular}{|c|c|}
\hline Method of preparation & Drug incorporated \\
\hline Ether Injection & $\begin{array}{c}\text { Sodium stibogluconate } \\
\text { Doxorubicin }\end{array}$ \\
\hline \multirow{2}{*}{ Hand Shaking } & Methotrexate \\
& Doxorubicin \\
\hline \multirow{2}{*}{ Sonication } & 9-desglycinamide \\
& 8-arginine \\
& Vasopressin \\
& Oestradiol \\
\hline
\end{tabular}

\section{Separation of Un entrapped Drug}

The removal of unentrapped solute from the vesicles can be accomplished by various techniques, which include:

Dialysis: The aqueous niosomal dispersion is dialyzed in dialysis tubing against phosphate buffer or normal saline or glucose solution [16].

Gel Filtration: The unentrapped drug is removed by gel filtration of niosomal dispersion through a Sephadex-G-50 column and elution with phosphate buffered saline or normal saline [16].

Centrifugation: The niosomal suspension is centrifuged and the supernatant is separated. The pellet is washed and then resuspended to obtain a niosomal suspension free from unentrapped drug [16].

\section{Characterization of Niosomes}

Size: Shape of niosomal vesicles is assumed to be spherical, and their mean diameter can be determined by using laser light scattering method.Also, diameter of thesevesicles can be determined by using electron microscopy, molecular sieve chromatography, ultracentrifugation, photon correlation microscopy, optical microscopy and freeze fracture electron microscopy [17].

Bilayer Formation: Assembly of non-ionic surfactants to form a bilayer vesicle is portrayed by X-cross formation under light polarization microscopy [17].

Number of Lamellae: This is determined by utilizing nuclear magnetic resonance (NMR) spectroscopy, small angle X-ray scattering and electron microscopy [17].

Membrane Rigidity: Membrane rigidity can be estimated by means of mobility of fluorescence probe as a function of temperature [17].

Entrapment Efficiency: The unentrapped medication is separated by dialysis, centrifugation, or gel filtration as described above and the medication which remained entrapped in niosomes is determined by complete vesicle disruption utilizing $50 \%$ n-propanol or $0.1 \%$ Triton X-100 and analyzing the resultant solution by appropriate assay technique for the medication [17].

Entrapment efficiency $=($ Amount entrapped $/$ total amount $) \times 100$ 
pH Measurement: The $\mathrm{pH}$ of niosomes can be measured by a $\mathrm{pH}$ meter. The $\mathrm{pH}$ estimation is performed at $25^{\circ} \mathrm{C}$ [17].

Zeta Potential Measurement: Zeta potential of suitably diluted niosome dispersion is carried out using zeta potential analyzer which is based on electrophoretic light scattering and laser Doppler velocimetry method. The temperature is set at $25^{\circ} \mathrm{C}$. The charge on vesicles and their mean zeta potential values can hence be determined directly [17].

\section{Advantages of Niosomes}

A. Niosomes are less costly compared to liposomes. They have higher chemical stability due to absence of phospholipids which are inclined to oxidative degradation.

B. Niosomes prolong the circulation of entrapped drug. They can be relied upon to target the drug to its wanted site of action and to control its discharge.

C. The use of niosomes in cosmetics preparation has the following advantages:

i. The vesicle suspension being water based offers more patient compliance over oil based systems.

ii. Since the structure of the niosome offers place to suit hydrophilic, lipophilic and in addition ampiphilic drug moieties, they can be utilized for an assortment of drugs.

iii. Niosome characteristics such as size, lamellarity etc. of the vesicle can be fluctuated relying upon the requirement.

iv. The vesicles can act as a depot to release the medication gradually and offer a controlled release.

D. They are osmotically active and stable.

E. They increase the stability of the entrapped drug

F. Handling and storage of surfactants do not require any special conditions

G. Can increase the oral bioavailability of drugs

H. Can enhance the skin penetration of drugs

I. They can be utilized for oral, parenteral and topical use

J. The surfactants are biodegradable, biocompatible, and nonimmunogenic

K. Improve the therapeutic action of the drug by shielding it from the biological environment and restrictions to target cells, in this manner diminishing the clearance of the drug [18].

\section{Applications of Niosomes}

Table 2

Table 2.

\begin{tabular}{|c|c|c|c|c|c|}
\hline No. & Application & Components & Method used & Drug used & Ref \\
\hline 1 & $\begin{array}{l}\text { Encapsulation and release of } \\
\text { hydrophilic and hydrophobic } \\
\text { anti-diabetic drugs }\end{array}$ & $\begin{array}{c}\text { Tween 80, phosphate } \\
\text { buffered saline (PBS), } \\
\text { fluoresceinisothiocyanate-dextran } \\
\text { (FITC-dextran) and cholesterol }\end{array}$ & $\begin{array}{l}\text { Thin film hydration } \\
\text { method }\end{array}$ & $\begin{array}{l}\text { Glipizide and } \\
\text { metformin } \mathrm{HCl}\end{array}$ & [19] \\
\hline 2 & As a drug delivery carrier & $\begin{array}{l}\alpha, \omega \text {-hexadecyl-bis-(1-aza-18- } \\
\text { crown-6) (bola), Span } 80 \text { and } \\
\text { cholesterol }\end{array}$ & $\begin{array}{l}\text { Thin layer evaporation } \\
\text { technique }\end{array}$ & 5-fluorouracil & {$[20]$} \\
\hline 3 & To increase bioavailability & $\begin{array}{l}\text { cholesterol, span } 60 \text {, and dicetyl } \\
\text { phosphate }\end{array}$ & Film hydration method & Acyclovir & {$[21]$} \\
\hline 4 & For brain targeting & $\begin{array}{l}\text { N-Palmitoyl Glucosamine (NPG), } \\
\text { span 60, cholesterol and solulan } \\
\text { C24 }\end{array}$ & $\begin{array}{l}\text { Probe sonication } \\
\text { method }\end{array}$ & $\begin{array}{c}\text { Vasoactive } \\
\text { intestinal peptide } \\
\text { (VIP) }\end{array}$ & {$[22]$} \\
\hline 5 & To prolong release time & Sorbitan esters & $\begin{array}{c}\text { Reverse phase } \\
\text { evaporation method }\end{array}$ & Rifampicin & [23] \\
\hline 6 & For drug targeting & $\begin{array}{l}\text { N-palmitoylglucosamine (NPG) } \\
\text {,sorbitanmonostearate, cholesterol } \\
\text { and cholesteryl poly-24- } \\
\text { oxyethylene ether. }\end{array}$ & Sonication method & Transferrin & {$[24]$} \\
\hline 7 & For anti inflammatory effect & $\begin{array}{c}\text { Span } 20 \text {, span } 60 \text {, cholesterol, } \\
\text { Carbopol } 934 \text {, chloroform ethanol, } \\
\text { potassium dihydrogen phosphate } \\
\text { and sodium hydroxide }\end{array}$ & $\begin{array}{l}\text { Thin film hydration } \\
\text { technique }\end{array}$ & Diclofenac sodium & [25] \\
\hline 8 & In anticancer therapy & Span 40 and cholesterol & $\begin{array}{l}\text { transmembrane } \mathrm{pH} \\
\text { gradient drug uptake } \\
\text { process }\end{array}$ & Vincristine & {$[26]$} \\
\hline 9 & In localized psoriasis & $\begin{array}{l}\text { Chitosan, phosphatidylcholine, } \\
\text { span } 60 \text {, cholesterol and } \\
\text { butylatedhydroxytoluene }\end{array}$ & $\begin{array}{l}\text { Lipid layer hydration } \\
\text { method }\end{array}$ & Methotrexate & {$[27]$} \\
\hline
\end{tabular}




\begin{tabular}{|c|c|c|c|c|c|}
\hline 10 & $\begin{array}{l}\text { In oral delivery of peptide } \\
\text { drugs }\end{array}$ & $\begin{array}{c}\text { Brij52, brij 72, brij 92, brij 76, } \\
\text { brij } 97, \text { brij } 85 \text {, brij } 35, \text { DCP and } \\
\text { cholesterol }\end{array}$ & Film hydration method & Insulin & {$[28]$} \\
\hline 11 & In diagnostic imaging & $\begin{array}{l}\text { N-palmitoyl glucosamine [NPG] } \\
\text { and PEG } 4400\end{array}$ & Ether injection method & Gadobenate & {$[14]$} \\
\hline 12 & $\begin{array}{c}\text { In transdermal drug delivery } \\
\text { system }\end{array}$ & $\begin{array}{c}\alpha, \omega \text {-hexadecyl-bis-(1-aza-18- } \\
\text { crown-6) (Bola-surfactant), Span } \\
80 \text { and cholesterol }\end{array}$ & $\begin{array}{l}\text { Thin layer evaporation } \\
\text { method }\end{array}$ & $\begin{array}{l}\text { Ammonium } \\
\text { glycyrrhizinate }\end{array}$ & [29] \\
\hline 13 & $\begin{array}{l}\text { In ophthalmic drug delivery } \\
\text { system }\end{array}$ & $\begin{array}{l}\text { Tween } 60 \text {, Tween } 80 \text {, Brij } 35 \text {, } \\
\text { cholesterol and a negative charge } \\
\text { inducer dicetyl phosphate (DCP) }\end{array}$ & $\begin{array}{l}\text { Thin film hydration } \\
\text { technique }\end{array}$ & Gentamicin & {$[30]$} \\
\hline 14 & For lung targeting & Span-85 and cholesterol & $\begin{array}{l}\text { Hand shaking method } \\
\text { and ether injection } \\
\text { method }\end{array}$ & Rifampicin & {$[31]$} \\
\hline 15 & In thrombolytic disease & $\begin{array}{l}\text { Hexadecyl poly(3)glycerol, DCP } \\
\text { and cholesterol }\end{array}$ & $\begin{array}{l}\text { Film hydration } \\
\text { technique }\end{array}$ & Urokinase & {$[32]$} \\
\hline 16 & For stability improvement & $\begin{array}{c}\text { Span 40, span } 60 \text {, brij } 72 \text { and } \\
\text { cholesterol }\end{array}$ & Ether injection method & Fluconazole & [33] \\
\hline 17 & $\begin{array}{c}\text { For sustained antiplatelet } \\
\text { effect }\end{array}$ & $\begin{array}{l}\text { Cholesterol, tween } 80 \text { and } \\
\text { stearylamine }\end{array}$ & $\begin{array}{l}\text { Lipid hydration } \\
\text { method }\end{array}$ & Indomethacin & {$[34]$} \\
\hline 18 & For liver targeting & $\begin{array}{l}\text { Span 60, cholesterol, and dicetyl } \\
\text { phosphate }\end{array}$ & $\begin{array}{l}\text { Thin film hydration } \\
\text { method }\end{array}$ & Ribavin & [35] \\
\hline 19 & $\begin{array}{c}\text { To increase entrapment } \\
\text { efficiency }\end{array}$ & $\begin{array}{l}\text { Span 60, cholesterol, and dicetyl } \\
\text { phosphate }\end{array}$ & $\begin{array}{l}\text { Thin film hydration } \\
\text { method }\end{array}$ & Ketoprofen & [36] \\
\hline 20 & To reduce toxicity & $\begin{array}{l}\text { Span 20, Span 40, Span } 60 \text { and } \\
\text { cholesterol }\end{array}$ & Film hydration method & Cefpodoximeproxetil & {$[37]$} \\
\hline
\end{tabular}

\section{Marketed Products}

Lancome has turned out with an assortment of anti-ageing

items which depend are niosome based. L'Oreal is also conducting research on anti-ageing cosmetic products [2] (Figure 7).

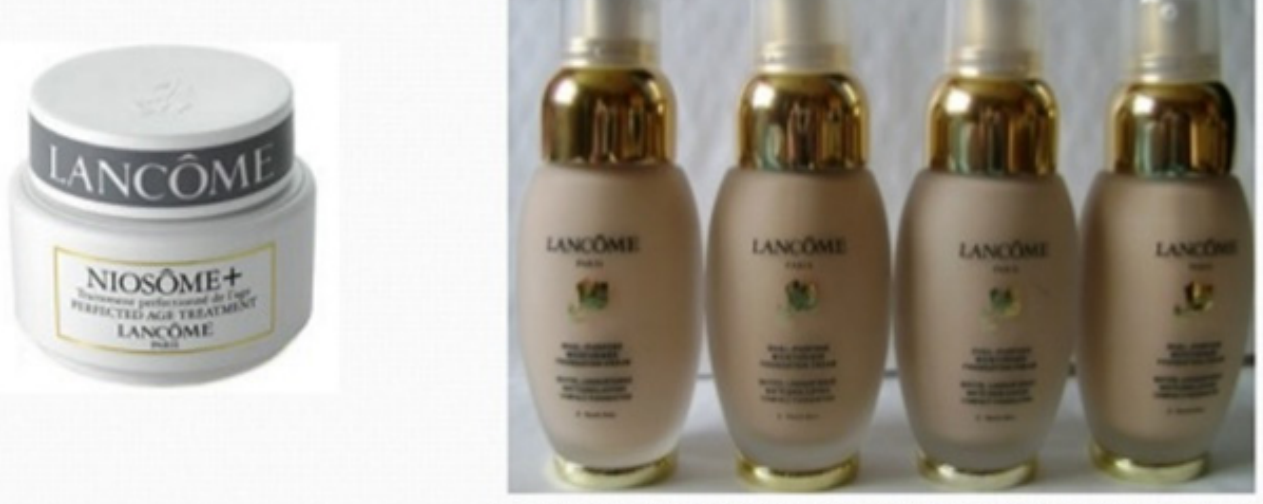

LANCOME FOUNDATION CREAM NIOSOME+

Figure 7.

\section{Future Prospects}

Niosomes represent a promising medication delivery module. Researched in noisome field are extensed to encapsulate toxic anticancer drugs, anti infective medications, anti AIDS medications, anti-inflammatory medications, anti viral medications, etc. Also, to utilize niosomes as promising medication transporters to accomplish better bioavailability, targeting properties, decreasing the toxicity, lethality and side effects of the medications. The ionic medications transporters are generally poisonous and inadmissible while niosomal carriers are more secure [38].

\section{Conclusion}

Niosomes drug delivery system is an effective approach towards novel drug delivery. Niosomes are composed mainly of non-ionic surfactants and cholesterol. Niosomes might be set up by different techniques like ether injection method, hand shaking method, sonication method, reverse phase evaporation method, remote loading method, extrusion method and micro fluidization method. The properties of niosomes are influenced by additives, methods of preparation, drug properties, amount, structure and type of surfactant utilized, cholesterol and resistance to osmotic pressure. 
Briefly, as a drug delivery device, compared to liposome's, niosomes are osmotically active and are quite stable chemically by their own as well as enhance the stability of the medication so entrapped and delivered. They don't require special conditions for handling, protection or storage and industrial manufacturing. Adjacent to this, they offer flexibility in structural characteristics (composition, fluidity, size), and can be composed as desired. Niosomes offer different favorable circumstances over other drug delivery devices and have found applicability in pharmaceutical field. It was thus concluded that niosomes are very effective drug delivery tools for incorporation/targeting of various therapeutically active moieties and the onus lies on future scientists to effectively harness its potential in diverse application areas for the benefit of humanity.

\section{References}

1. Mujoriya, Rajesh Z, Kishor Dhamandeb, RB Bodla (2011) Niosomal drug delivery system-a review. Int J Appl Pharm 3: 7-10,

2. Chandu V Pola, A Arunachalam, S Jeganath, K Yamini, K Tharangini, et al. (2012) Niosomes: a novel drug delivery system. Int J Novel Trends Pharmaceutical Sci 2: 25-31.

3. Uchegbu, Ijeoma F, Aikaterini Lalatsa, Dennis Wong (2013) Polymeric nanoparticles. Fundamentals of pharmaceutical nanoscience. Springer, New York, USA 211-234.

4. Anupriya Kapoor (2016) An overview on Niosomes-A novel vesicular approach for Ophthalmic Drug Delivery. Pharma Tutor 4(2): 28-33.

5. Tangri Pranshu, Shaffi Khurana (2011) Niosomes: formulation and evaluation. International Journal of Biopharmaceutics 2(1): 47-53.

6. Robinson, Joseph, Vincent HL Lee (1987) Controlled drug delivery: fundamentals and applications. CRC Press, New York.

7. Baillie AJ, Florence AT, Hume LR, Muirhead GT, Rogerson A (1985) The preparation and properties of niosomes-non-ionic surfactant vesicles. Journal of pharmacy and pharmacology 37(12): 863-868.

8. I Chhotalal Kalpesh, Kalpesh Ashara, Jalpa Paun, Vishal P Mendapara (2014) Vesicular Drug Delivery System: A Novel Approach.

9. Biju SS, Sushama Talegaonkar, PR Mishra, RK Khar (2006) Vesicular systems: an overview. Indian Journal of Pharmaceutical Sciences 68(2)?

10. Hu, Chengjiu, David G Rhodes (1999) Proniosomes: a novel drug carrier preparation. International journal of pharmaceutics 185(1): 23-35.

11. Arora Rajnish (2007) Advances in niosome as a drug carrier: a review. Asian Journal of Pharmaceutics (AJP)1(1).

12. Soussan Elodie, Cassel S, Blanzat M, Rico Lattes I (2009) Drug delivery by soft matter: matrix and vesicular carriers. Angewandte Chemie International Edition 48(2): 274-288.]

13. Yeo Pei Ling, Chooi Ling Lim, Soi Moi Chye, Anna Pick Kiong Ling, Rhun Yian Koh (2018) Niosomes: a review of their structure, properties, methods of preparation, and medical applications. Asian Biomedicine 11(4): 301-314?

14. Rajera Rampal, Nagpal K, Singh SK, Mishra DN (2011) Niosomes: a controlled and novel drug delivery system. Biological and Pharmaceutical Bulletin 34(7): 945-953.

15. Abdelkader, Hamdy, Adam WG Alani, Raid G Alany (2014) Recent advances in non-ionic surfactant vesicles (niosomes): self-assembly, fabrication, characterization, drug delivery applications and limitations. Drug delivery 21(2): 87-100.)

16. NVS Madhav, A Saini (2011) Niosomes: a novel drug delivery system. Int J Res Pharm Chem 1(3): 498-511.
17. Sjöblom Johan (Eds.) (2012) Emulsions: A Fundamental and Practical Approach. Springer Science \& Business Media.

18. Verma Navneet Kumar, Asha Roshan (2014) Niosomes and its application: A review. International J of research in Pharmacy and life sciences 2(1): 182-184.

19. Samed N, Sharma V, Sundaramurthy A (2017) Hydrogen bonded niosomes for encapsulation and release of hydrophilic and hydrophobic anti-diabetic drugs: An efficient system for oral anti-diabetic formulation. Applied Surface Science 449: 567-573.

20. Cosco D, Paolino D, Muzzalupo R, Celia C, Citraro R, et al. (2009) Novel PEG-coated niosomes based on bola-surfactant as drug carriers for 5-fluorouracil. Biomedical microdevices 11(5): 1115-1125.

21. Attia Ismail A, Sanaa A El Gizawy, Medhat A Fouda, Ahmed M Donia (2007) Influence of a niosomal formulation on the oral bioavailability of acyclovir in rabbits. AAPS Pharm Sci Tech 8(4): 206-212.]

22. Kamath MP, BD Shenoy, SB Tiwari, R Karki, N Udupa, et al. (2000) Prolonged release biodegradable vesicular carriers for rifampicinformulation and kinetics of release. Indian Journal of Experimental Biology 38: 113-118.

23. Dufes Christine, Gaillard F, Uchegbu IF, Schätzlein AG, Olivier JC, et al. (2004) Glucose-targeted niosomes deliver vasoactive intestinal peptide (VIP) to the brain. International journal of pharmaceutics 285(1-2): 7785 .

24. Dufes Christine, Andreas G Schätzlein, Laurence Tetley, Alexander I Gray, Dave G Watson, et al. (2000) Niosomes and polymeric chitosan based vesicles bearing transferrin and glucose ligands for drug targeting. Pharmaceutical research 17(10): 1250-1258.]

25. Marwa, Abdallah, Sammour Omaima, EL-Ghamry Hanaa, Abu-Selem Mohammed (2013) Preparation and in-vitro evaluation of diclofenac sodium niosomal formulations. International Journal of Pharmaceutical Sciences and Research 4(5): 1757-1765.

26. Parthasarathi G, Udupa N, Umadevi P, Pillai GK (1994) Niosome encapsulated of vincristine sulfate: improved anticancer activity with reduced toxicity in mice. Journal of drug targeting 2(2): 173-182.]

27. Lakshmi PK, Devi GS, Bhaskaran S, Sacchidanand S (2007) Niosomal methotrexate gel in the treatment of localized psoriasis: phase I and phase II studies. Indian Journal of Dermatology Venereology and Leprology 73(3): 157-161.

28. Pardakhty, Abbas, Jaleh Varshosaz, Abdolhossein Rouholamini (2007) In vitro study of polyoxyethylene alkyl ether niosomes for delivery of insulin. International journal of pharmaceutics 328(2): 130-141.

29. Paolino Donatella, Muzzalupo R, Ricciardi A, Celia C, Picci N, et al. (2007) In vitro and in vivo evaluation of Bola-surfactant containing niosomes for transdermal delivery. Biomedical microdevices 9(4): 421-433.

30. Abdelbary Ghada, Nashwa El-gendy (2008) Niosome-encapsulated gentamicin for ophthalmic controlled delivery. Aaps Pharmscitech 9(3): 740-747.

31. Jain CP, SP Vyas (1995) Preparation and characterization of niosomes containing rifampicin for lung targeting. Journal of microencapsulation 12(4): 401-407.

32. Erdoğan Suna, A Yekta Özer, Hasan Bilgili (2005) In vivo behaviour of vesicular urokinase. International journal of pharmaceutics 295(1-2): $1-6$.

33. Gupta Madhu, Vaidya B, Mishra N, Vyas SP (2011) Effect of surfactants on the characteristics of fluconazole niosomes for enhanced cutaneous delivery. Artificial Cells Blood Substitutes and Biotechnology 39(6): 376384.

34. Pillai Gopal K, Maher LD Salim (1999) Enhanced inhibition of platelet aggregation in-vitro by niosome-encapsulated indomethacin. International journal of pharmaceutics 193(1): 123-127? 
35. Hashim Fahima, El Ridy M, Nasr M, Abdallah Y (2010) Preparation and characterization of niosomes containing ribavirin for liver targeting. Drug delivery 17(5): 282-287.

36. Ahmad Mohammad Zaki, Akhter S, Jain GK, Rahman M, Pathan SA, et al. (2010) Metallic nanoparticles: technology overview \& drug delivery applications in oncology. Expert opinion on drug delivery 7(8): 927-942.]
37. Sambathkumar R, Perumal Perumal, V. Sekharbabu, R.V.M. Manikander et al. (2011) Development and evaluation of cefpodoxime proxetil niosomes using various sorbitan esters. Res J Pharm Biol and Chem Sci 2: 213-219.

38. Mandal, Subhash C, Miitreyee Mandal (2010) Current status and future prospects of new drug delivery system. Pharma Times Magazine 42: 136 .)

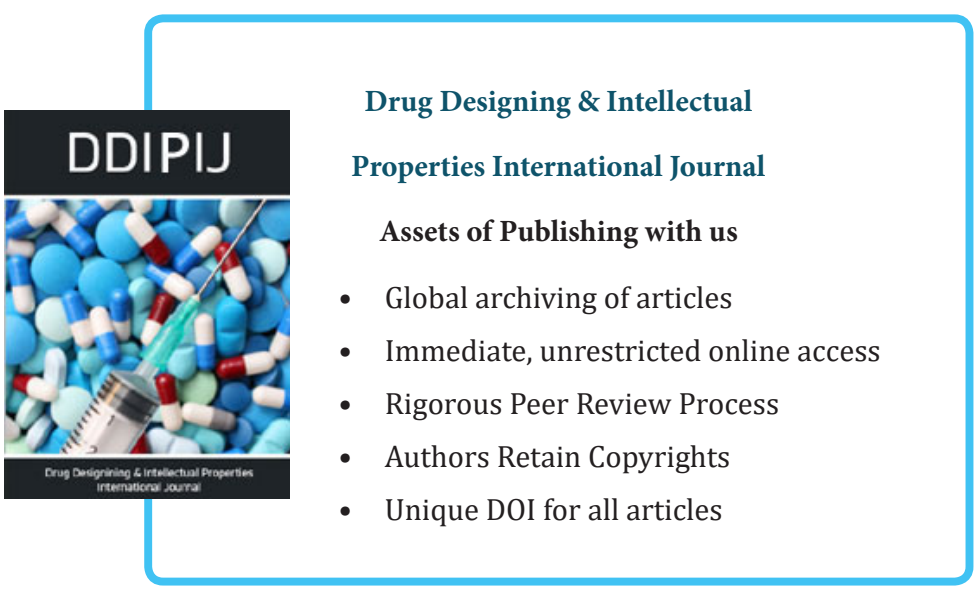

